\title{
Mansouramycin $\mathbf{C}$ kills cancer cells through reactive oxygen species production mediated by opening of mitochondrial permeability transition pore
}

\author{
Shan Kuang ${ }^{1,2}$, Ge Liu ${ }^{1,2,3}$, Ruobing Cao ${ }^{1,2,3}$, Linlin Zhang ${ }^{1,2,3}$, Qiang Yu ${ }^{4}$ and Chaomin \\ Sun $^{1,2}$ \\ ${ }^{1}$ Key Laboratory of Experimental Marine Biology, Institute of Oceanology, Chinese Academy of Sciences, Qingdao, China \\ ${ }^{2}$ Laboratory for Marine Biology and Biotechnology, Qingdao National Laboratory for Marine Science and Technology, Qingdao, \\ China \\ ${ }^{3}$ College of Earth Science, University of Chinese Academy of Sciences, Beijing, China \\ ${ }^{4}$ Division of Tumor Pharmacology, Shanghai Institute of Materia Medica, Chinese Academy of Sciences, Shanghai, China \\ Correspondence to: Chaomin Sun, email: sunchaomin@qdio.ac.cn \\ Keywords: mansouramycin C, marine-derived isoquinolinequinone, reactive oxygen species, mitochondrial permeability transition \\ pore, anticancer drug \\ Received: May 17, $2017 \quad$ Accepted: October 02, $2017 \quad$ Published: October 24, 2017 \\ Copyright: Kuang et al. This is an open-access article distributed under the terms of the Creative Commons Attribution License \\ 3.0 (CC BY 3.0), which permits unrestricted use, distribution, and reproduction in any medium, provided the original author and \\ source are credited.
}

\section{ABSTRACT}

Cancer is one of the deadliest diseases in the world and the search for novel anticancer agents is urgently required. Marine-derived isoquinolinequinones have exhibited promising anticancer activities. However, the exact mechanisms of cytotoxic activities of these isoquinolinequinones are poorly characterized. In this study, we investigated the anticancer effects and molecular mechanisms of mansouramycin $C$ $(\mathrm{Mm} \mathrm{C})$, a cytotoxic isoquinolinequinone isolated from a marine streptomycete. We demonstrated that $\mathrm{Mm} \mathrm{C}$ preferentially killed cancer cells and the cytotoxic effects were mediated by reactive oxygen species (ROS) generation. Mass spectrometry based proteomic analysis of Mm C-treated A549 cells revealed that many ROS-related proteins were differentially expressed. Proteomic-profiling after $\mathbf{M m ~ C}$ treatment identified oxidative phosphorylation as the most significant changes in pathways. Analysis also revealed extensive defects in mitochondrial structure and function. Furthermore, we disclosed that Mm C-induced ROS generation was caused by opening of mitochondrial permeability transition pore. Notably, Mm C synergized with sorafenib to induce cell death in A549 cells. Hence, we propose that the marine-derived natural compound $\mathrm{Mm} \mathrm{C}$ is a potent inducer of the mitochondrial permeability transition and a promising anticancer drug candidate. Moreover, molecular mechanisms of $\mathbf{M m ~ C ~}$ shed new light on the understanding of the cytotoxic mechanisms of marine-derived isoquinolinequiones.

\section{INTRODUCTION}

Cancer is a major cause of morbidity and mortality with approximately 14 million new cases and 8 million cancer-related deaths in 2012 worldwide [1]. It is estimated that compared with 2012, the annual number of new cancers will grow by $70 \%$ by 2035 [1]. Lung cancer remains the most common cancer in 2012 worldwide, both in term of new cases (1.8 million cases, $12.9 \%$ of total) and deaths (1.6 million deaths, $19.4 \%$ of total) [2]. Thus, the search for more effective anticancer drugs, especially lung cancer drugs, is urgently required.

Natural products have long been an important source of anticancer drugs. A detailed analysis of 
anticancer drugs approved from around the 1940s to 2014 revealed that of the 175 small molecules approved 85, or $49 \%$, were either natural products or their derivatives [3]. Marine biodiversity is extremely rich. The described marine species are approximately 230,000 to 275,000 and the inventory is accruing 1,300 to 1,500 species per year [4], which indicates a striking potential for anticancer drug discovery. However, marine biodiversity is poorly explored and discovery of marine natural compounds has only begun: approximately 22,000 natural products of marine origin have been discovered so far, whereas 131,000 terrestrial natural products exist [5]. Also, marine natural compounds which have either been marketed or under development are relatively few. To date, there are only seven approved marine-derived pharmaceuticals in clinical use and four of them are anticancer drugs [6]. It might therefore be attractive to further explore marine natural compounds for anticancer drug development.

Selectivity remains a big challenge in cancer treatment. Accumulating evidence suggests that increase of reactive oxygen species (ROS) is effective for selective cancer therapy [7-9]. Compared with their normal counterparts, most cancer cells are under oxidative stress with increased production of ROS [10, 11]. Severe increase of ROS could cause irreversible oxidative damage of cells leading to cell death [12]. When both cancer and normal cells are exposed to equal intensity of exogenous ROS stimulating agents, the ROS levels in cancer cells would be more easier to reach a threshold to trigger death [13]. The vast majority of anticancer drugs such as ionizing radiation agents, most chemotherapeutic agents and some targeted agents kill their target cells directly or indirectly through the generation of elevated amounts of intracellular ROS [14]. Many ROS inducers are currently under various stages of drug development [12]. Among them, clinical use of $\mathrm{As}_{2} \mathrm{O}_{3}$ in acute promyelocytic leukemia (APL) has advanced to first-line therapy [15].

Mitochondrial energy metabolism is the most quantitatively important source of intracellular ROS under physiological conditions [16]. In addition to their established role in energy metabolism, mitochondria are main actors in cell death [17]. In this context, permeabilization of the inner mitochondrial membranean event regulated by the mitochondrial permeability transition pore (PTP) - plays a central role in cell death $[18,19]$. PTP is a multiprotein complex built up among membranes of mitochondria and allows molecules with a molecular weight of less than $1.5 \mathrm{kD}$ to pass freely into and out of the inner membranes of mitochondria [19, 20]. Opening of PTP causes mitochondrial permeability transition (MPT), which leads to dissipation of mitochondrial membrane potential (MMP), uncoupling of oxidative phosphorylation and increase in mitochondrial volume (swelling). The PTP open-closed transition is modulated by a variety of factors. $\mathrm{Ca}^{2+}$ and oxidant stress are key factors of MPT induction [21, 22], while the PTP inhibitor cyclosporin A (Cs A) has become the standard diagnostic tool for the characterization of the PTP [23].

Mansouramycin C (Mm C, 3-carbomethoxy7-methylaminoisoquinoline-5, 8-dione) is a natural isoquinolinequinone isolated from marine-derived Streptomyces sp. isolate Mei37 [24]. Among the four isolated mansouramycins (mansouramycin A-D), Mm $\mathrm{C}$ is the most active cytotoxic compound, with a mean $\mathrm{EC}_{50}$ value of $89 \mathrm{nM}$ against 36 tumor cell lines tested [24]. However, the molecular targets and mode of action of $\mathrm{Mm} \mathrm{C}$ remain unclear. Many marine-derived isoquinolinequinones, including renierone, cribrostatins, perfragilins and caulibugulones, are attractive due to their anticancer properties [25-28]. Nevertheless, the exact mechanisms of action of these marine-derived cytotoxic isoquinolinequinones are poorly characterized $[29,30]$. Thus, elucidation of the molecular mechanisms of Mm C will be helpful to understand the cytotoxic mechanisms of these isoquinolinequiones.

In the present study, we synthesized $\mathrm{Mm} \mathrm{C}$ and investigated the molecular targets and mode of action of it. It preferentially killed cancer cells through induction of ROS. In addition, $\mathrm{Mm} \mathrm{C}$ caused functional and structural defects of mitochondria. Finally we demonstrated that $\mathrm{Mm} \mathrm{C}$ induced ROS production through opening of mitochondrial PTP. Notably, Mm C synergized with sorafenib to inhibit cancer cell growth. Our data strongly supports the notion that $\mathrm{Mm} \mathrm{C}$ is a novel inducer of MPT and is a promising anticancer drug candidate.

\section{RESULTS}

\section{Mm C preferentially kills cancer cells}

$\mathrm{Mm} \mathrm{C}$ (Figure 1A) is a natural isoquinolinequinone isolated from a marine streptomycete with potent cytotoxic activity [24]. To investigate its mode of action and therapeutic potential, we tested the effects of Mm C on human cancer and normal cells. Interestingly, Mm C preferentially killed cancer cells including human lung cancer cells A549, liver cancer cells Bel-7402 and cervical cancer cells HeLa compared with normal cells including human embryonic lung fibroblasts WI-38, liver cells LO2 and embryonic kidney cells HEK-293T. As shown in Figure $1 \mathrm{~B}$, treatment with $2.5 \mu \mathrm{M} \mathrm{Mm} \mathrm{C}$ for $6 \mathrm{~h}$ caused about $50 \%$ or more decrease of the MTT value of cancer cell lines, whereas it had very little growth inhibition effect on normal cell lines.

We chose the most sensitive cell line A549 as our model to investigate the molecular mechanisms of $\mathrm{Mm} \mathrm{C}$. In the MTT assay, the growth inhibitory effect of Mm C on A549 cells for $6 \mathrm{~h}$ was concentration-dependent, with a $50 \%$ inhibitory concentration value of $749.3 \mathrm{nM}$ (Figure 1C). In the trypan blue exclusion staining assay, $\mathrm{Mm} \mathrm{C}$ also dose-dependently inhibited the growth of A549 cells with an $\mathrm{EC}_{50}$ of $814.8 \mathrm{nM}$ (Supplementary Figure 1A). Also, 
we treated cells with $\mathrm{Mm} \mathrm{C}$ for $6 \mathrm{~h}$, then removed $\mathrm{Mm} \mathrm{C}$ and incubated cells with fresh medium for another $24 \mathrm{~h}$. Cell viability was determined by MTT assay and the $\mathrm{EC}_{50}$ was calculated to be $457.0 \mathrm{nM}$ (Supplementary Figure 1B), which is lower than the $\mathrm{EC}_{50}$ of $\mathrm{Mm} \mathrm{C}$ for $6 \mathrm{~h}$, suggesting that $\mathrm{Mm} \mathrm{C}$ might cause cell death of A549 cells.

Annexin V-FITC/ propidium iodide (PI) doublestaining assays showed that treatment of Mm C for $6 \mathrm{~h}$ dose-dependently caused cell death of cancer cells (Figure 1D). As shown in Figure 1D, for HeLa cells, Mm C mainly caused apoptosis; for Bel-7402 cells, Mm C mainly caused necrosis while for A549 cells, Mm C only caused necrosis. As for normal cells, $5 \mu \mathrm{M}$ Mm C caused necrosis of LO2 cells while it had little effects on WI-38 and HEK-293T cells (Figure 1D). Taken together, these data showed that $\mathrm{Mm} \mathrm{C}$ selectively killed cancer cells.

\section{ROS contributes to the cytotoxic effects of $\mathrm{Mm} \mathrm{C}$}

ROS have been proven to be effective for selective cancer therapy according to the threshold theory [13]. Therefore, we examined the effects of Mm C on intracellular ROS levels of A549 cells using flow cytometry and a fluorescent probe, 2', 7'-dichlorofluorescin diacetate ( $\left.\mathrm{DCFH}_{2}-\mathrm{DA}\right)$. Indeed, $\mathrm{Mm}$ $\mathrm{C}$ induced accumulation of intracellular ROS in a dose(Figure 2A) and time-dependent (Figure 2B) manner. Notably, Mm C had extremely strong ROS stimulation potency. As shown in Figure 2A, treatment with $5 \mu \mathrm{M} \mathrm{Mm}$ $\mathrm{C}$ for $6 \mathrm{~h}$ resulted in a 43-fold increase of ROS-associated fluorescence intensity in A549 cells. Also, intracellular ROS levels continued to increase until $6 \mathrm{~h}$ after Mm C treatment (Figure 2B). While compared with A549 cells, $\mathrm{Mm} \mathrm{C}$ induced much less ROS generation in normal cells (Supplementary Figure 2).

Intracellular glutathione (GSH) is the major antioxidant reagent in cells which plays major roles to maintain redox status and defend against oxidative stress. Therefore, we investigated the roles of GSH in Mm C-mediated ROS formation. As shown in Figure 2C and 2D, Mm C dose- and time-dependently decreased the intracellular levels of GSH in A549 cells. The time
A<smiles>CNC1=CC(=O)c2cc(C(=O)OC)ncc2C1=O</smiles>

$\mathrm{C}$

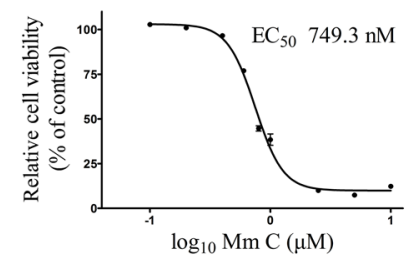

$\mathrm{D}$

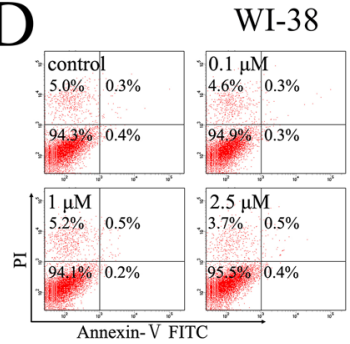

HeLa
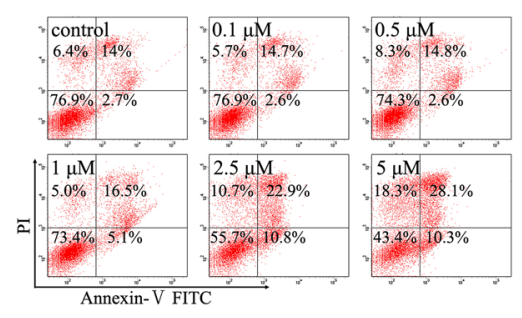

$\mathrm{B}$

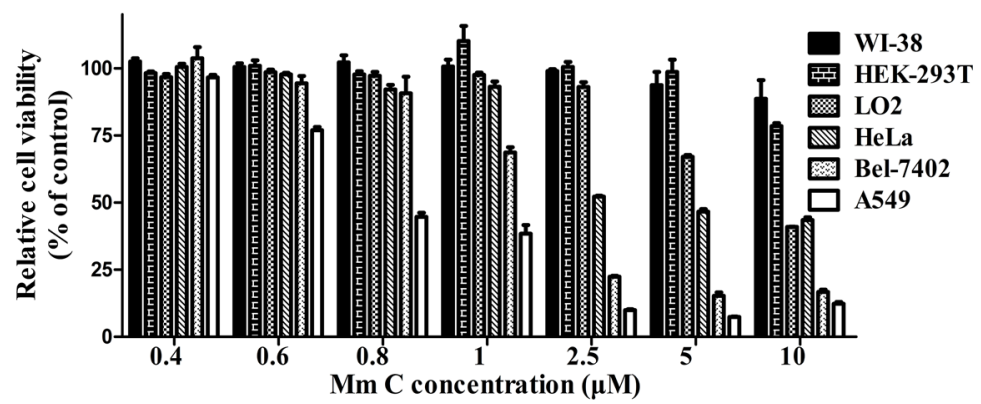

HEK-293T
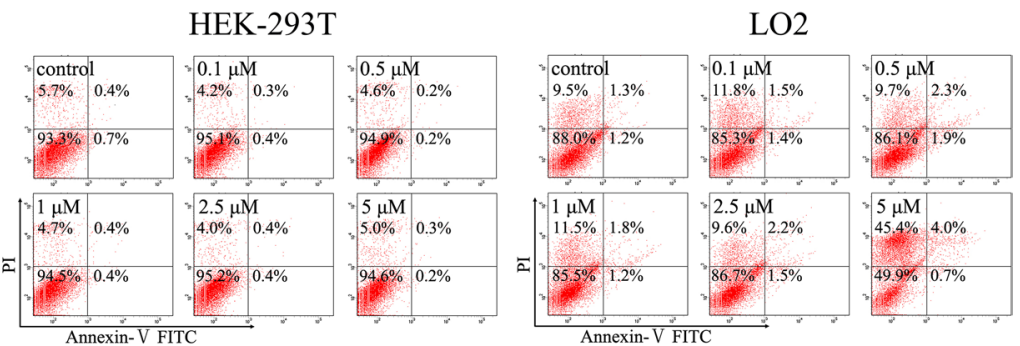

Bel-7402
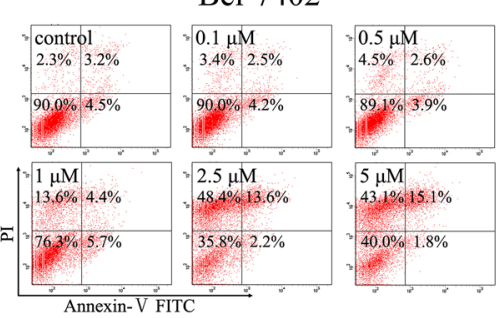

A549

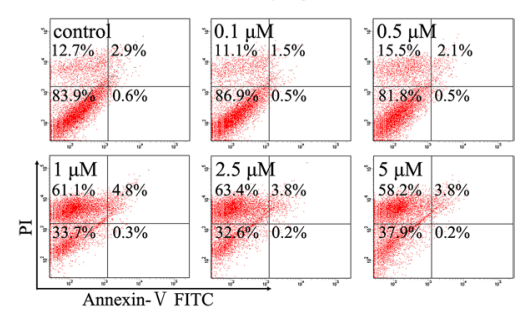

Figure 1: Mm C preferentially killed cancer cells. (A) Chemical structure of Mm C. (B) Distinct cytotoxic effects of Mm C on normal cell lines Wi-38, HEK-293T and LO2 and cancer cell lines HeLa, Bel-7402 and A549 for 6 h determined by MTT assay. (C) EC Fo $_{50}$ $\mathrm{Mm} \mathrm{C}$ on viability of A549 cells for $6 \mathrm{~h}$ determined by MTT assay. (D) Flow cytometric analysis of Mm C-treated cells. Different normal cells as well as cancer cells were pretreated with indicated concentrations of $\mathrm{Mm} \mathrm{C}$ for $6 \mathrm{~h}$. Cells were then stained with Annexin V-FITC and PI before analysis of cell death through flow cytometry. 

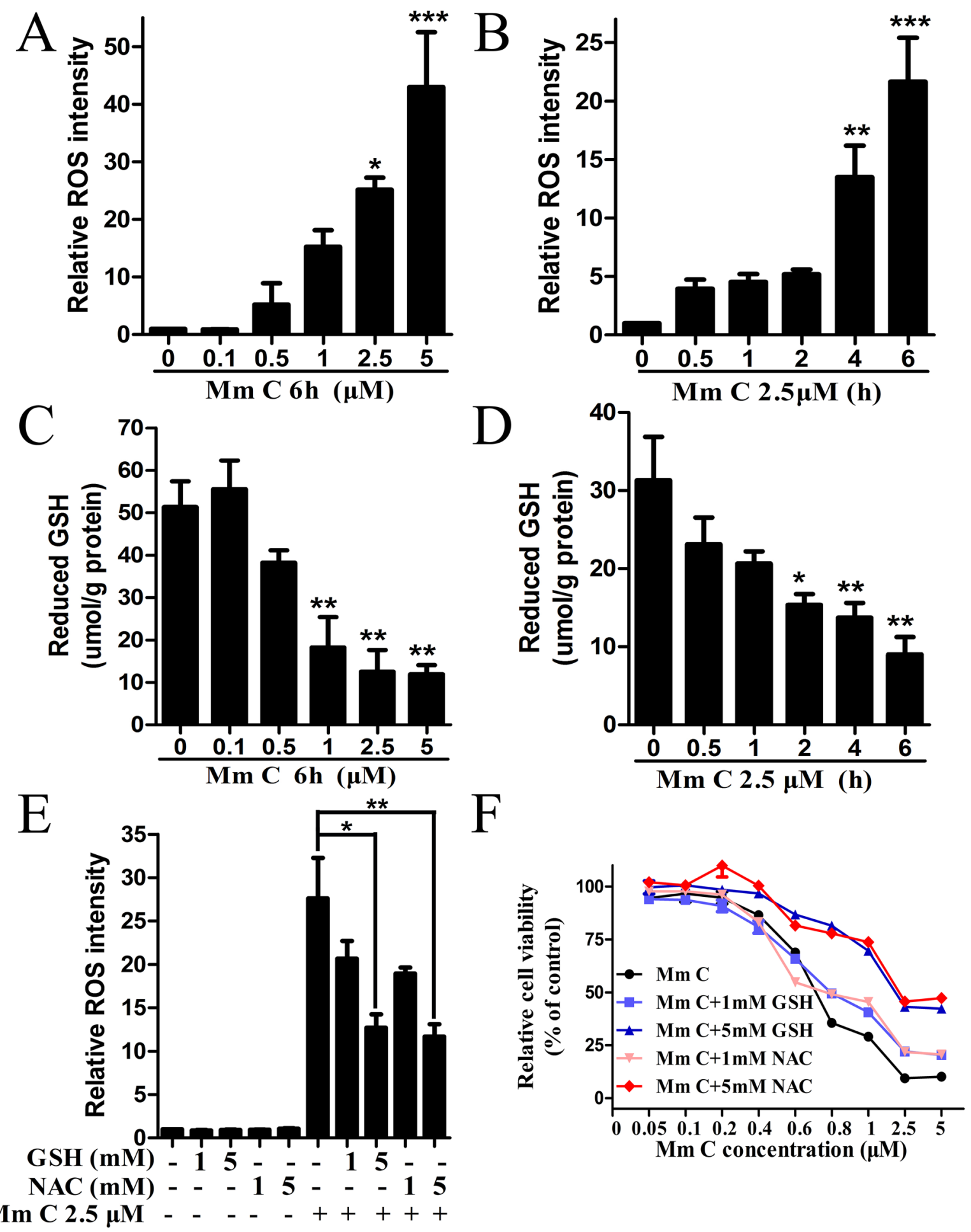

Figure 2: ROS contributed to the cytotoxic effect of Mm C. (A, B) Mm C dose- (A) and time-dependently (B) induced accumulation of ROS. A549 cells were treated with Mm C and then ROS levels were measured by flow cytometry. ${ }^{*} \mathrm{P}<0.05,{ }^{* *} \mathrm{P}<0.01$, ${ }^{* * *} \mathrm{P}<0.001$ compared with control. (C, D) Mm C dose- (C) and time-dependently (D) decreased intracellular GSH levels. A549 cells were treated with $\mathrm{Mm} \mathrm{C}$ and then intracellular GSH levels were measured by a DTNB reaction kit and quantified by protein levels measured using the Bradford method. ${ }^{*} \mathrm{P}<0.05,{ }^{* *} \mathrm{P}<0.01$ compared with control. (E) ROS scavengers reduced Mm C-induced ROS formation. A549 cells were pretreated with the indicated concentrations of GSH or NAC for $1 \mathrm{~h}$ and then $\mathrm{Mm} \mathrm{C}$ was added for another $4 \mathrm{~h}$. The ROS levels were measured by flow cytometry. ${ }^{*} \mathrm{P}<0.05,{ }^{* *} \mathrm{P}<0.01$. (F) ROS scavengers prevented the cytotoxic effect of Mm C. A549 cells were pretreated with the indicated concentrations of GSH or NAC for $1 \mathrm{~h}$ and then the indicated concentrations of Mm $\mathrm{C}$ were added for another $6 \mathrm{~h}$. Cell viability was measured using the MTT method. 
course of ROS production synchronized with that of GSH reduction, suggesting that these two events occurred simultaneously (Figure 2B and 2D).

To further establish the correlation between $\mathrm{Mm}$ $\mathrm{C}$-induced ROS generation and cell growth inhibition, we investigated the effects of ROS scavengers on Mm C-treated A549 cells. Pretreatment of A549 cells with GSH and N-acetyl-L-cysteine (NAC) partially abolished the $\mathrm{Mm} \mathrm{C}$-induced elevation of ROS in a dose-dependent manner (Figure 2E). Also, both GSH and NAC dose-dependently abrogated Mm C-mediated growth inhibition of A549 cells (Figure 2F). However, $5 \mathrm{mM}$ GSH or NAC cannot totally abolish the elevation of ROS or inhibition of cell growth caused by $\mathrm{Mm} \mathrm{C}$ (Figure $2 \mathrm{E}$ and $2 \mathrm{~F}$ ), probably due to the extremely strong ROS stimulation potency of Mm C. These data indicated that accumulation of intracellular ROS contributed to the cytotoxic effects of Mm C.

Cytochrome b-c1 complex subunit 7

Reactive oxygen species modulator 1

$\mathrm{NADH}$ dehydrogenase [ubiquinone] iron-sulfur protein $8 /$ mitochondrial

Cytochrome b-c1 complex subunit 9

Mitochondrial 2-oxoglutarate/malate carrier protein Cytochrome $c$ oxidase subunit 7A2/ mitochondrial Delta(24)-sterol reductase ATP synthase $F(0)$ complex subunit $B 1 /$ mitochondrial Rho-related GTP-binding protein RhoB ATP synthase subunit epsilon-like protein/ mitochondrial $\mathrm{NADH}$ dehydrogenase [ubiquinone] 1 beta subcomplex subunit 4 Cystatin-C Sulfiredoxin-1 Ferritin heavy chain

Cytochrome c oxidase subunit 7A-related protein/ mitochondrial ATP synthase $\mathrm{F}(0)$ complex subunit $\mathrm{C} 1 /$ mitochondrial NADH dehydrogenase [ubiquinone] 1 alpha subcomplex subunit 12 Dual specificity protein phosphatase 1 Transcription factor AP-1

\section{Proteomic analysis of differentially expressed proteins after $\mathrm{Mm} \mathrm{C}$ treatment}

To better describe the contributions of ROS induction to the effects of $\mathrm{Mm} \mathrm{C}$, we performed a proteomic study to identify differentially expressed proteins after Mm C treatment. We treated A549 cells with $1 \mu \mathrm{M} \mathrm{Mm} \mathrm{C}$ for $6 \mathrm{~h}$ and $12 \mathrm{~h}$ respectively and found that 89 and 134 proteins were differently expressed (1.2-fold change cutoff and $\mathrm{p}$ value less than 0.05 , Supplementary Table 1 and 2). All these differently expressed proteins were screened to identify ROS-related proteins and 19 proteins were filtered and clustered (Figure 3). In detail, 10 of the 19 proteins are subunits of complex I, III, IV of mitochondrial electron transport chain (ETC) as well as complex $\mathrm{V}$ and were up-regulated after $\mathrm{Mm} \mathrm{C}$ treatment. These results agree well with previous study that oxidative stress plays a critical role in the increase of mitochondria abundance of human cancer cells [31]. Reactive oxygen

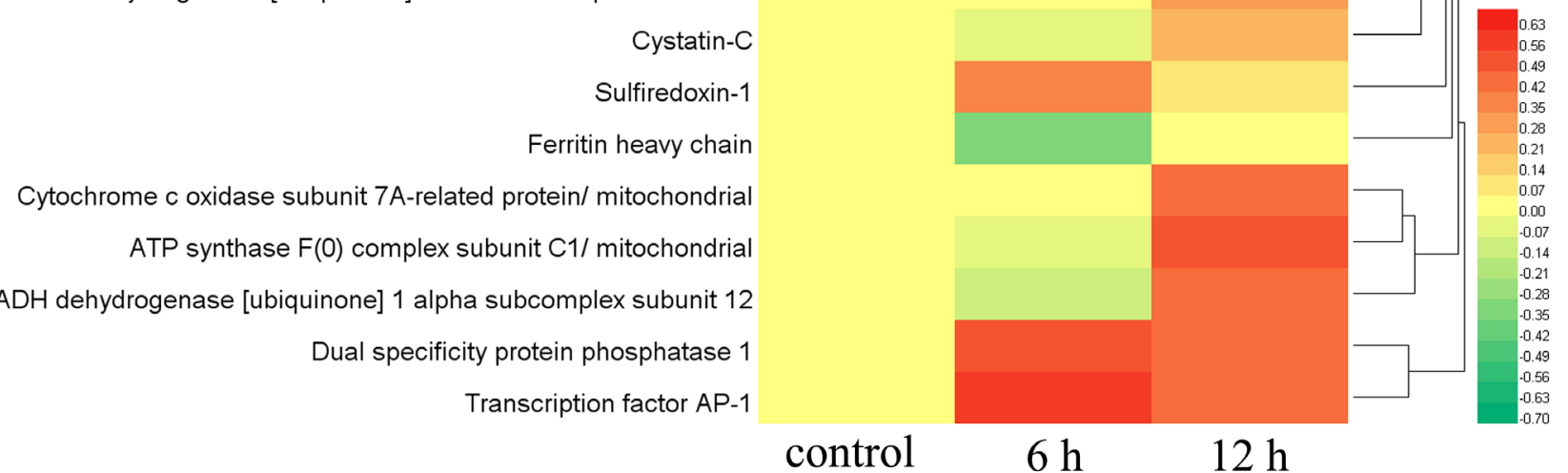

Figure 3: Proteomic, clustering and heatmap analysis of differentially expressed ROS-related proteins after Mm C treatment. A549 cells were treated with $1 \mu \mathrm{M} \mathrm{Mm} \mathrm{C}$ for $6 \mathrm{~h}$ or $12 \mathrm{~h}$ and then proteins extracted from whole cell lysates were separated and identified using LC-ESI-MS/MS analysis. The relative protein abundances of differentially expressed ROS-related proteins (fold change $\geq 1.2$ or fold change $\leq 0.83$ and $\mathrm{p}$ value $<0.05$ ) were imported for clustering analysis using HemI. Hierarchical clustering of proteins was displayed by average linkage and euclidean distance metrics and color scales of $\log 2$ values were shown. Each line represented one protein. 
species modulator 1 , which is known to induce ROS production [32], were up-regulated. While ferritin heavy chain was down-regulated, well-correlated with previous study that down-regulation of ferritin heavy chain increases oxidative stress [33]. Three ROS scavengers, delta(24)-sterol reductase, 2-oxoglutarate/malate carrier protein and sulfiredoxin-1, were up-regulated [34-36]. Cystatin-C, rho-related GTP-binding protein Rho B, dual specificity protein phosphatase 1 and transcription factor AP-1, which act downstream of ROS production [37-40], were up-regulated.

To illustrate pathways involved in the effects of $\mathrm{Mm}$ C. Kyoto Encyclopedia of Genes and Genomes (KEGG) orthology terms were assigned to the proteomic datasets by the KAAS sever and the KEGG mapper to map the pathways (Figure 4A). The most significant changes in pathways after $\mathrm{Mm} \mathrm{C}$ treatment involved oxidative phosphorylation ( $\mathrm{p}$ value 0.0017 ), which was induced in the presence of Mm C (Figure 4A and 4B). The pathway analysis confirmed the heatmap analysis of the differently expressed ROS-related proteins after Mm C treatment, suggesting that ROS is the major effect of Mm C-treated A549 cells.

\section{Mm C caused functional and structural defects of mitochondria}

Proteomic analysis of differentially expressed proteins after $\mathrm{Mm} \mathrm{C}$ treatment indicated that mitochondrial complex proteins, which are the main actors in ATP production, were significantly elevated. We therefore examined the effects of $\mathrm{Mm} \mathrm{C}$ on intracellular ATP levels. As shown in Figure 5A and 5B, Mm C dose- and timedependently decreased the intracellular ATP levels in A549 cells. Since mitochondrial membrane potential (MMP) is known to be essential for the production of ATP via oxidative phosphorylation. We analyzed the effects of $\mathrm{Mm}$ $\mathrm{C}$ on MMP of A549 cells and found it dose- and timedependently declined (Figure 5C and 5D). The decrease of intracellular ATP levels and MMP in A549 cells after Mm $\mathrm{C}$ treatment indicate defects in mitochondrial function.

Next, the ultrastructural morphology of mitochondria in Mm C-treated A549 cells was observed by transmission electron microscopy. As shown in Figure $5 \mathrm{E}$, control cells $(\mathrm{i}, \mathrm{ii})$ contained small, morphologically normal, round or oval mitochondria with regular distribution of cristae. While Mm C-treated cells (iii,

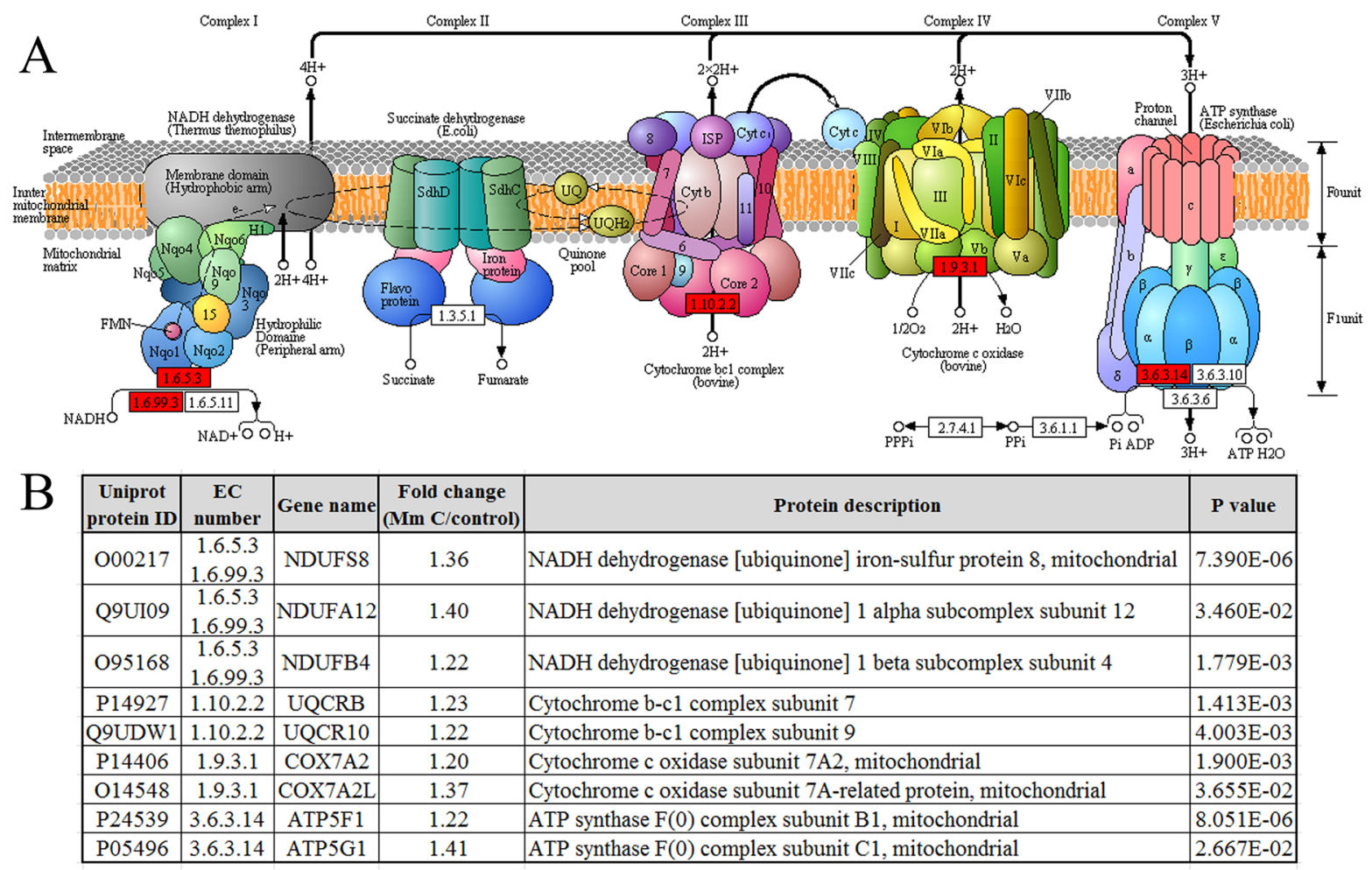

Figure 4: Proteomic and pathway analysis of differentially expressed proteins after $\mathrm{Mm} \mathrm{C}$ treatment using the Kyoto Encyclopedia of Genes and Genomes (KEGG) Pathway database. (A) A549 cells were treated with $1 \mu \mathrm{M} \mathrm{Mm} \mathrm{C}$ for $12 \mathrm{~h}$ and then altered proteins were depicted in oxidative phosphorylation pathway. Up-regulated (fold change $\geq 1.2$ and $p$ value $<0.05$ ) or nonregulated proteins were shown in red or white, respectively. (B) List of the altered proteins after Mm C treatment which related to oxidative phosphorylation. 
iv and v, vi) showed enlarged mitochondria with cristal disorganization (iv) or loss (vi), outer membrane buckling and distorted shape. These data indicated that $\mathrm{Mm} \mathrm{C}$ caused structural defects of mitochondria in A549 cells.

The effects of $\mathrm{Mm} \mathrm{C}$ on mitochondrial function were also assessed by monitoring the respiration rate of cells as well as isolated mouse mitochondria. Oxygen consumption rate (OCR) was detected using a Clark electrode. As shown in Figure 6A, Mm C dosedependently increased respiration rate of A549 cells. Also, we determined whether $\mathrm{Mm} \mathrm{C}$ acted directly on mitochondria, we isolated mouse liver mitochondria and found that $1 \mu \mathrm{M} \mathrm{Mm} \mathrm{C}$ significantly stimulated respiration rate of mitochondria (Figure 6B). Mitochondrial uncoupler carbonyl cyanide m-chlorophenyl hydrazone (CCCP), which results in respiration proceeding without phosphorylation, also stimulates mitochondrial OCR. So we compared Mm C with CCCP and found that $1 \mu \mathrm{M} \mathrm{Mm}$ $\mathrm{C}$ increased mitochondrial OCR to a similar degree as 5 $\mu \mathrm{M}$ CCCP (Figure 6B).

To determine whether Mm $\mathrm{C}$ transported protons across the mitochondrial inner membrane as CCCP did, we performed mitochondrial swelling assays in isotonic potassium acetate buffer supplied with the potassium ionophore valinomycin. We first confirmed the necessary role of valinomycin in CCCP induced proton-dependent mitochondrial swelling (Supplementary Figure 3). As shown in Figure 6C, CCCP induced mitochondrial swelling represented by the downward deflection of absorbance at $600 \mathrm{~nm}$. However, Mm C had no effects on mitochondrial swelling (Figure 6C), indicating that $\mathrm{Mm} \mathrm{C}$ stimulated mitochondrial respiration not through a protonophoric mechanism.

\section{Mm C induced ROS production in mouse liver mitochondria through opening of mitochondrial permeability transition pore (PTP)}

In addition to uncoupler, mitochondrial respiration can also be stimulated through opening of mitochondrial permeability transition pore (PTP). Opening of mitochondrial PTP causes unlimited proton movement across the inner mitochondrial membrane which results in uncoupling of oxidative phosphorylation. Since $\mathrm{Ca}^{2+}$ is essential for mitochondrial PTP opening, we tested the opening of mitochondrial PTP at different $\mathrm{Ca}^{2+}$ concentrations and chose the concentration of $20 \mu \mathrm{M}$ in the following experiments (Supplementary Figure 4). Next, we examined whether Mm C could modulate mitochondrial PTP using isolated mouse liver
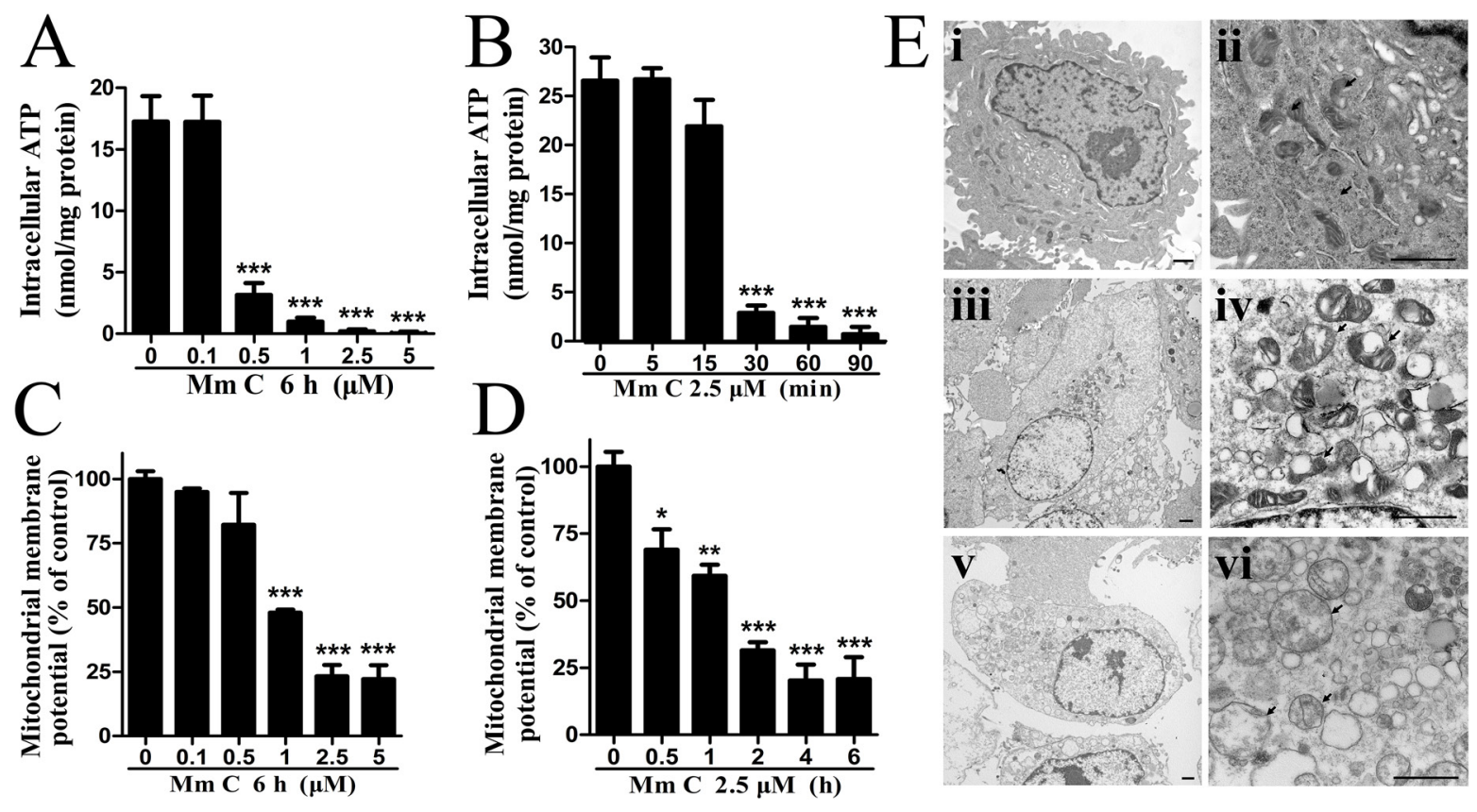

Figure 5: Mm C caused functional and structural defects of mitochondria. (A, B) Mm C dose- (A) and time-dependently (B) decreased intracellular ATP levels. A549 cells were treated with Mm C and then intracellular ATP levels were determined by a chemiluminescence assay and quantified by protein levels measured using the Bradford method. ${ }^{* * *} \mathrm{P}<0.001$ compared with control. (C, D) $\mathrm{Mm} \mathrm{C}$ dose- (C) and time-dependently (D) decreased mitochondrial membrane potential (MMP). A549 cells were treated with Mm C and then the MMP was measured by fluorescent probe JC-1 and flow cytometry. ${ }^{*} \mathrm{P}<0.05,{ }^{* *} \mathrm{P}<0.01,{ }^{* * *} \mathrm{P}<0.001$ compared with control. (E) Mm C caused mitochondrial structural defects. A549 cells (i, ii) were treated with $2.5 \mu \mathrm{M} \mathrm{Mm} \mathrm{C}$ for $2 \mathrm{~h}$ (iii, iv) or $6 \mathrm{~h}$ (v, vi) and then cells were harvested, fixed, and photographed by transmission electron microscopy. ii, iv and vi are high-power images for i, iii and v, respectively. Arrows indicate mitochondria and black scale bar is $1 \mu \mathrm{M}$. 
mitochondria in isotonic sucrose solution supplied with 20 $\mu \mathrm{M} \mathrm{Ca}^{2+}$. Opening of mitochondrial PTP was monitored by the changes of absorbance at $540 \mathrm{~nm}$, which reflected mitochondrial permeabilization to sucrose. As shown in Figure 7A, Mm C dose-dependently induced opening of mitochondrial PTP as revealed by decrease in light scattering due to mitochondrial swelling. Also, as shown in Figure 7B, the induction of mitochondrial swelling by $\mathrm{Mm} \mathrm{C}$ was inhibited by cyclosporine A (Cs A), an inhibitor of the mitochondrial PTP, indicating that mitochondrial swelling induced by $\mathrm{Mm} \mathrm{C}$ was mediated through opening of mitochondrial PTP.

Since ROS is closely relevant to PTP opening, we tested whether Mm C could modify mitochondrial production of ROS indicated by the fluorescence changes of $\mathrm{DCFH}_{2}$-DA. As shown in Figure $7 \mathrm{C}$, addition of $\mathrm{DCFH}_{2}$-DA to respiring mitochondria in swelling buffer with $20 \mu \mathrm{M} \mathrm{Ca}^{2+}$ led to linear increase in fluorescence over

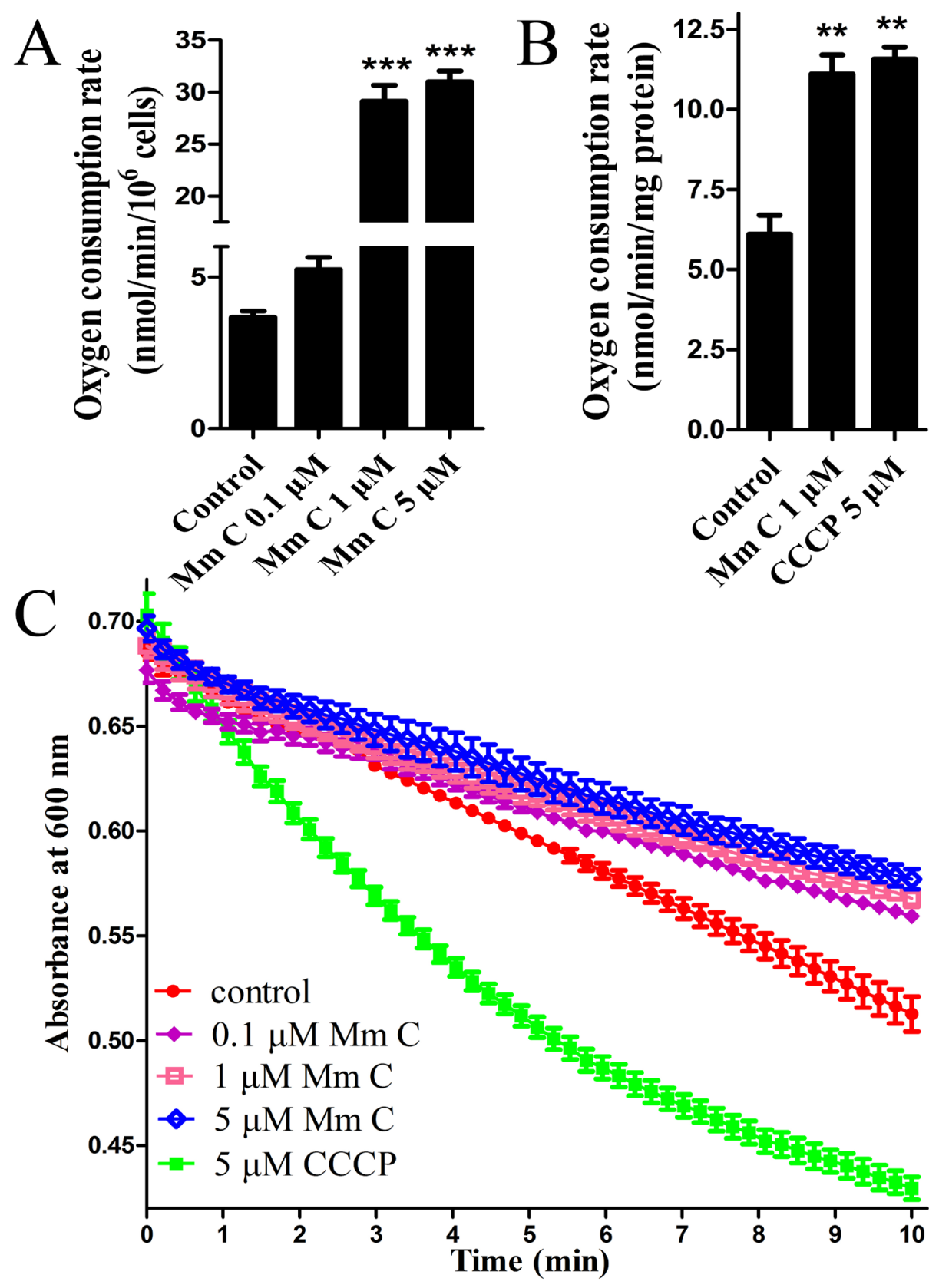

Figure 6: Mm C stimulated oxygen consumption rate (OCR) of cells and mouse liver mitochondria. (A) Mm C stimulated OCR of A549 cells. OCR of A549 cells treated with indicated concentrations of Mm C was measured using a Clark-type oxygen electrode (Hansatech, King's Lynn, Norfolk, UK). ${ }^{* * *} \mathrm{P}<0.001$ compared with control. (B) Mm C stimulated OCR of isolated mitochondria energized with glutamate and malate. OCR of mouse liver mitochondria treated with Mm C or CCCP was measured. ${ }^{* *} \mathrm{P}<0.01 \mathrm{compared}$ with control. (C) Unlike CCCP, Mm C did not induce proton-dependent mitochondrial swelling. Isolated mouse liver mitochondria were treated with $\mathrm{Mm} \mathrm{C}$ or CCCP in hyposmotic potassium acetate medium and then absorbance at $600 \mathrm{~nm}$ was recorded over $10 \mathrm{~min}$. 

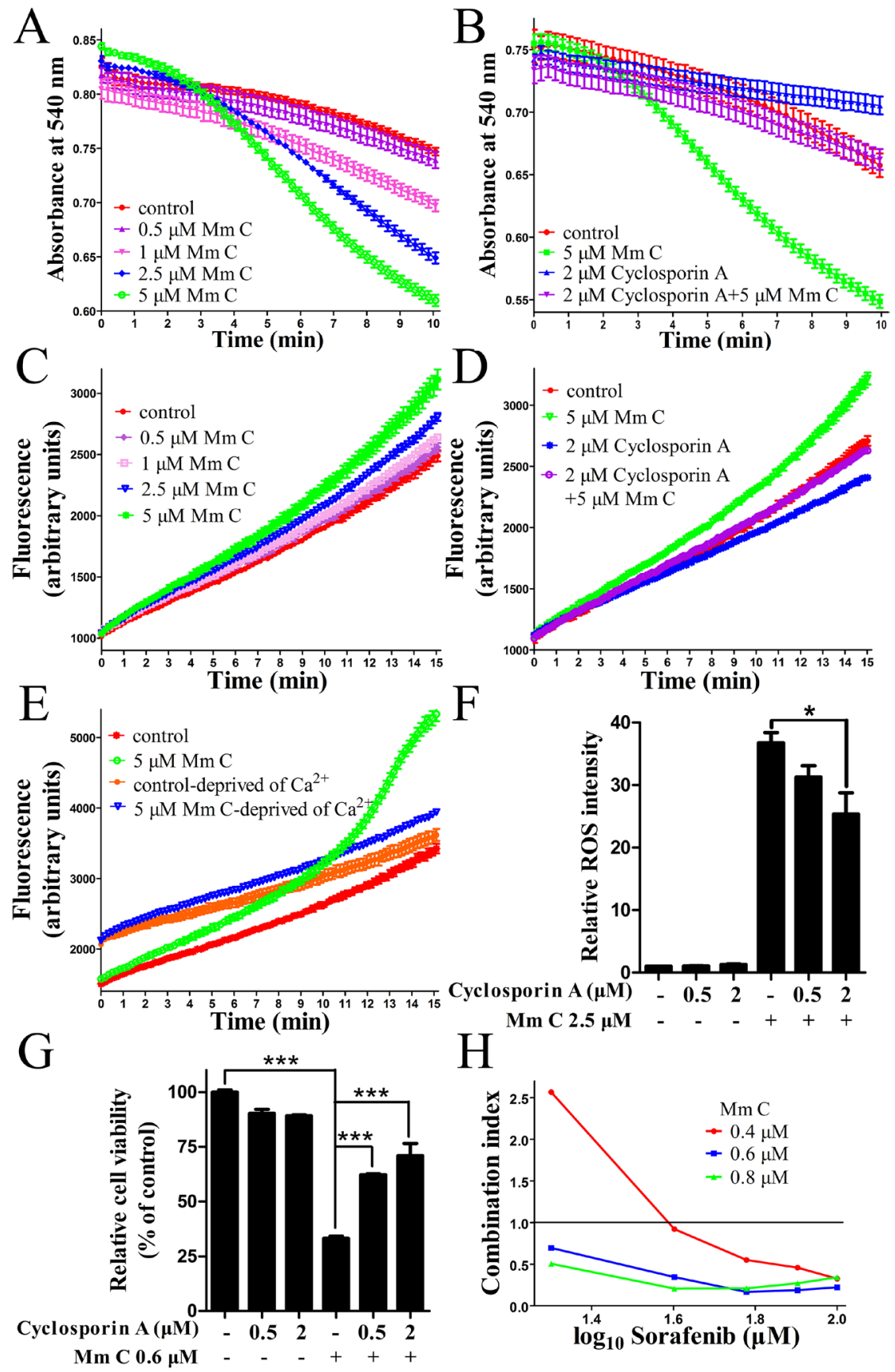

Figure 7: Mm C induced ROS production through opening of mitochondrial permeability transition pore (PTP). (A) $\mathrm{Mm} \mathrm{C}$ dose-dependently induced mitochondrial permeability transition (MPT) in isolated mitochondria. Mouse liver mitochondria incubated with $\mathrm{Ca}^{2+}$ were treated with indicated concentrations of $\mathrm{Mm} \mathrm{C}$ and then absorbance at $540 \mathrm{~nm}$ was recorded over $10 \mathrm{~min}$. (B) The induction of MPT in isolated mitochondria by Mm C can be abolished by cyclosporin A (Cs A) treatment. Mouse liver mitochondria incubated with $\mathrm{Ca}^{2+}$ were treated with $\mathrm{Mm} \mathrm{C}, \mathrm{Cs} \mathrm{A}$ or combination of $\mathrm{Mm} \mathrm{C}$ and $\mathrm{Cs} \mathrm{A}$. Then absorbance was recorded. (C) $\mathrm{Mm} \mathrm{C}$ dosedependently induced ROS accumulation in isolated mitochondria. Mouse liver mitochondria incubated with $\mathrm{Ca}^{2+}$ were treated with indicated concentrations of $\mathrm{Mm} \mathrm{C}$ and then fluorescence was recorded over $15 \mathrm{~min}$. (D) Mm C-induced ROS accumulation in isolated mitochondria can be abolished by Cs A treatment. Mouse liver mitochondria incubated with $\mathrm{Ca}^{2+}$ were treated with $\mathrm{Mm} \mathrm{C}$, Cs A or combination of $\mathrm{Mm} \mathrm{C}$ and Cs A. Then fluorescence was recorded. (E) $\mathrm{Ca}^{2+}$ is essential for Mm C-induced ROS accumulation in isolated mitochondria. Mouse liver mitochondria incubated with or without $\mathrm{Ca}^{2+}$ were treated with $\mathrm{Mm} \mathrm{C}$. Then fluorescence was recorded. (F) Cs A reduced Mm C-induced ROS production in A549 cells. A549 cells were pretreated with the indicated concentrations of Cs A for $1 \mathrm{~h}$ and then Mm $\mathrm{C}$ was added for another $4 \mathrm{~h}$. The ROS levels were measured by flow cytometry. ${ }^{*} \mathrm{P}<0.05$. (G) Cs A prevented the cytotoxic effect of Mm C. A549 cells were treated with Mm C, Cs A or Mm C together with Cs A for $24 \mathrm{~h}$ and cell viability was measured using the MTT method. ${ }^{* * *} \mathrm{P}<0.001$. (H) Mm C and sorafenib synergized to induce cell death in A549 cells. A549 cells were treated with Mm C, sorafenib or Mm $\mathrm{C}$ together with sorafenib for $24 \mathrm{~h}$ and cell viability was measured using the MTT method. Combination index (CI) was calculated with CompuSyn software. 
time, reflecting ROS formation due to basal mitochondrial respiration. Addition of $\mathrm{Mm} \mathrm{C}$ dose-dependently increased the fluorescence (Figure 7C), indicating that Mm C directly induced ROS production in mitochondria. Additionally, Cs A reversed the increase of fluorescence induced by $\mathrm{Mm}$ $\mathrm{C}$ (Figure 7D), demonstrating that $\mathrm{Mm} \mathrm{C}$ induced ROS production through opening of mitochondrial PTP.

Increased oxidative stress is one of the key mediators of compound-induced mitochondrial permeability transition (MPT), therefore, we assessed the causal relationship between the two effects of $\mathrm{Mm} \mathrm{C}$ : the induction of MPT and mitochondrial ROS production. Since mitochondrial PTP opening is dependent on $\mathrm{Ca}^{2+}$, we examined whether the effects of $\mathrm{Mm} \mathrm{C}$ on mitochondrial ROS production were dependent on the presence of $\mathrm{Ca}^{2+}$. As shown in Figure 7E, Mm C greatly increased fluorescence in the presence of $\mathrm{Ca}^{2+}$, while fluorescence induction was significantly weakened when $\mathrm{Ca}^{2+}$ was deprived. These data indicated that ROS production was mainly a consequence of MPT induction.

Also, we confirmed the causal relationship between MPT and ROS production in A549 cells. As shown in Figure 7F, pretreatment of A549 cells with Cs A dosedependently abolished $\mathrm{Mm} \mathrm{C}$-induced elevation of ROS, indicating that ROS production was primarily a consequence of MPT induction. Also, Cs A dosedependently abrogated Mm C-mediated cytotoxic effect of A549 cells (Figure 7G). These data indicated that Mm $\mathrm{C}$ induced ROS production and cytotoxicity of A549 cells through induction of MPT.

Since cancer cells frequently have multiple genetic alterations, a combination of different anticancer agents might be required to effectively cancer therapy. We combined $\mathrm{Mm} \mathrm{C}$ with multi-kinase inhibitor sorafenib as well as anti-microtubule drug paclitaxel and found that $\mathrm{Mm} \mathrm{C}$ and sorafenib synergized to induce cell death in A549 cells (Supplementary Figure 5). As shown in Figure $7 \mathrm{H}$, CI (combination index) $<1$, indicating synergy, was detected in the combination of $\mathrm{Mm} \mathrm{C}$ and sorafenib at most concentrations of each drug. Since ROS inducer tetrandrine was reported to have synergistic antitumor effect with sorafenib through ROS/Akt signaling [41], the ROS production effect of $\mathrm{Mm} \mathrm{C}$ probably contributed to the synergistic effect of $\mathrm{Mm} \mathrm{C}$ and sorafenib. The synergistic effect of $\mathrm{Mm} \mathrm{C}$ and sorafenib opens new opportunity to enhance the effectiveness of sorafenib in cancer treatment.

\section{DISCUSSION}

In marine microorganisms, the class actinobacteria is especially notable for containing organisms producing diverse natural products. In actinomycets, the genus Streptomyces produces $70 \%$ to $80 \%$ of currently characterized actinomycete natural products [42]. Mm $\mathrm{C}$ is a cytotoxic isoquinolinequinone isolated from a marine streptomycete. However, the exact mechanisms of action of $\mathrm{Mm} \mathrm{C}$ and most marine-derived cytotoxic isoquinolinequinones are still unknown. In the present study, we synthesized Mm C and investigated its molecular targets and mode of action. We demonstrate that $\mathrm{Mm} \mathrm{C}$ is a novel inducer of MPT, which increases ROS production and preferentially kills cancer cells.

PTP opening appears to be accompanied by a burst of $\operatorname{ROS}[43,44]$, and it is well known that oxidant stress is one of the key factors that favor induction of MPT [22], so it seems difficult to distinguish the primary cause to secondary effect of Mm C-induced PTP opening and

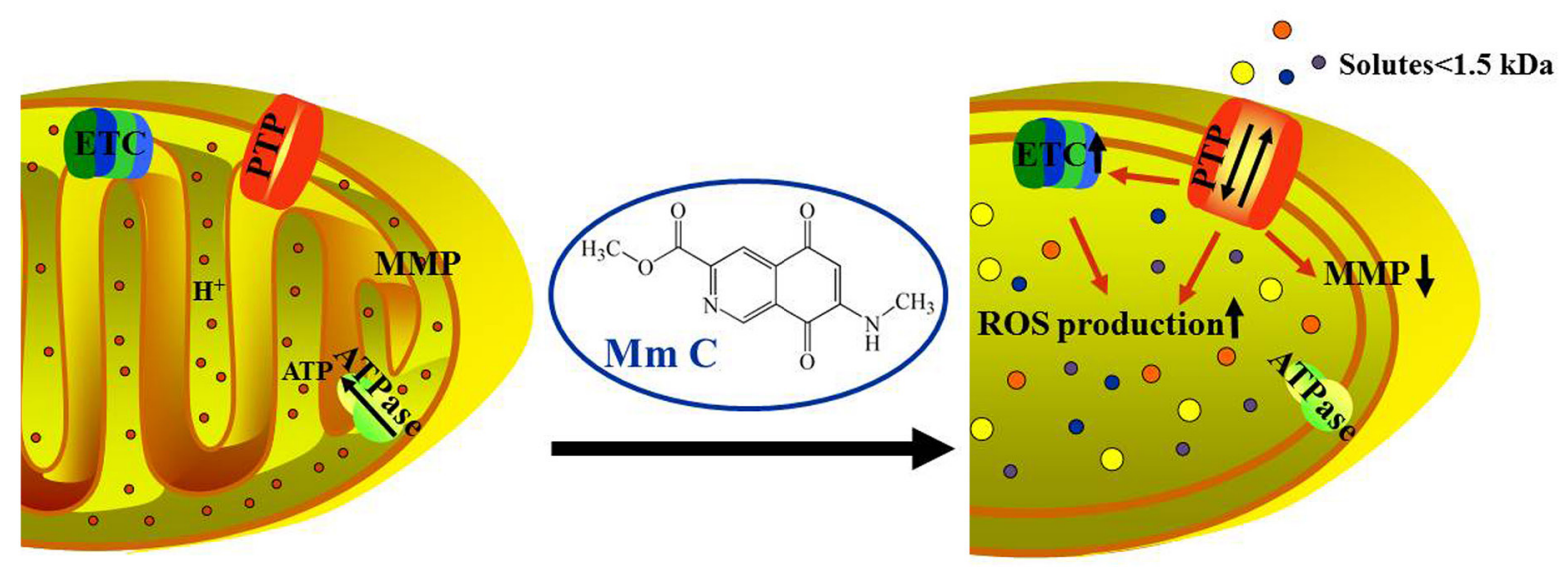

Figure 8: Proposed mechanism of Mm C. After compound uptake, Mm C induces opening of mitochondrial PTP which causes ROS production, decrease of MMP and mitochondrial structural (enlarged mitochondria with cristal disorganization or loss) and functional (increased respiration without accompanying ATP production) defects. Mitochondrial functional defects stimulate expression of ETC proteins and cellular respiration, which in turn facilitate the production of ROS. The opening of mitochondrial PTP, accumulation of ROS and mitochondrial dysfunction finally lead to cell death. (In the figure, small red circles indicate hydrogen ions and circles with other colors indicate all molecules with molecular weight less than $1.5 \mathrm{kD}$.) 
ROS production of mitochondria. However, we have several lines of evidence suggesting that ROS production is mainly a consequence of MPT induction. Firstly, Mm C-induced ROS production in both mitochondria and A549 cells could be inhibited by $\mathrm{Cs}$ A, an inhibitor of the mitochondrial PTP. Secondly, $\mathrm{Ca}^{2+}$, which is the single most important factor for PTP opening in vitro, was essential for $\mathrm{Mm} \mathrm{C}$-induced mitochondrial ROS production. Although $\mathrm{Mm} \mathrm{C}$ slightly increased mitochondrial ROS when $\mathrm{Ca}^{2+}$ was deprived, it is probably that the isolated mitochondria contain residual endogenous $\mathrm{Ca}^{2+}$. Lastly, a ubiquinone-binding site has been proven to regulate the mitochondrial PTP and ubiquinone has similar structure to $\mathrm{Mm} \mathrm{C}$, which all belong to quinones $[45,46]$. We propose that Mm C targets mitochondrial PTP to cause MPT and results in mitochondrial ROS production, which in turn facilitates the opening of PTP [22]. Thus, we speculate that PTP opening induced by $\mathrm{Mm} \mathrm{C}$ rapidly propagates to the whole cell, leading to a massive oxidative stress which preferentially kills cancer cells.

Mm C resulted in a 43-fold increase of ROS fluorescence intensity in A549 cells and the intensity of Mm C-induced ROS accumulation is much higher than that of other compounds [7-9]. Also, our proteomic results showed that many differentially expressed proteins were closely related to ROS, indicating ROS is the major effect in Mm C-treated cancer cells. Mm C stimulated the expression of ETC proteins and cellular respiration which may compensate for the decline of mitochondrial respiratory function, especially the decrease of intracellular ATP levels [47]. Mitochondrial ETC is the major sites of endogenous ROS production as a byproduct of respiration [16], so the stimulated expression of ETC proteins and cellular respiration caused by $\mathrm{Mm} \mathrm{C}$ further increased ROS production (Figure 8), accounting for the extremely high intensity of $\mathrm{Mm} \mathrm{C}$-induced $\mathrm{ROS}$ accumulation.

The opening of mitochondrial PTP induced by $\mathrm{Mm} \mathrm{C}$ resulted in a sudden increase in permeability of the mitochondrial inner membrane, leading to dissipation of MMP and this in turn promoted the opening of PTP [48]. Therefore, Mm C-induced MPT caused rapid and expanding decrease of MMP, which stimulated uncoupled respiration and decreased intracellular ATP levels and finally caused mitochondrial dysfunction.

It is difficult to determine the exact order of effects of $\mathrm{Mm} \mathrm{C}$ in cancer cells for that these effects entangle together and influence each other. However, we hypothesize that the primary target of $\mathrm{Mm} \mathrm{C}$ is mitochondrial PTP. As shown in Figure 8, the opening of PTP caused by Mm C induces ROS production as well as mitochondrial dysfunction and these two events promote each other to preferentially kill cancer cells.

In summary, our data reveals that $\mathrm{Mm} \mathrm{C}$, a marinederived natural compound isolated from Streptomyces sp. isolate Mei37, preferentially kills cancer cells through mitochondrial PTP opening-mediated ROS production. Furthermore, Mm C acts synergistically with anticancer drug sorafenib. These data strongly indicate that $\mathrm{Mm} \mathrm{C}$ is a promising anticancer drug candidate.

\section{MATERIALS AND METHODS}

\section{Reagents}

Mm C was synthesized by Shanghai SIMR Biotech. Co., Ltd (Shanghai, China) with a purity of $95.65 \%$ (Supplementary Figure 6). MTT, sorafenib, reduced glutathione (GSH) detection kit, BCA kit for protein quantification, intracellular ATP detection kit and JC-1 MMP detection kit were from Beyotime Institute of Biotechnology (Shanghai, China). Annexin V-FITC/ PI apoptosis detection kit was from Nanjing KeyGEN Biotech. Co., Ltd. (Nanjing, Jiangsu, China). GSH, rotenone and cyclosporine A (Cs A) were from Solarbio Science \& Technology Co., Ltd (Beijing, China). NAC was from Aladdin Biotech (Beijing, China). Carbonyl cyanide m-chlorophenyl hydrazone (CCCP) was from abcam (Cambridge, MA, USA). Valinomycin was from Sangon Biotech (Shanghai, China).

\section{Cell lines and culture}

All cell lines were obtained from the American Type Culture Collection. A549 cells were grown in RPMI 1640 medium (from Gibico, Grand Island, NY, USA) supplemented with 10\% FBS (from Gibico, Grand Island, NY, USA), $100 \mu \mathrm{g} / \mathrm{ml}$ streptomycin and 100 units/ml penicillin (from Hyclone, Logan, UT, USA). WI-38, HEK-293T, LO2, HeLa and Bel-7402 cells were cultured in Dulbecco's modified Eagle medium (DMEM, from Gibico) supplemented with 10\% FBS, $100 \mu \mathrm{g} / \mathrm{ml}$ streptomycin and 100 units $/ \mathrm{ml}$ penicillin. All cell lines were cultured at $37^{\circ} \mathrm{C}$ in a humidified atmosphere of $5 \%$ $\mathrm{CO}_{2}$ and $95 \%$ air.

\section{Cell viability measurement}

Cell viability was measured by MTT assay as well as trypan blue exclusion staining. Briefly, about 500012000 logarithmically growing cells were placed into 96-well plates and cultured for $24 \mathrm{~h}$. Cells were then treated with vehicle control (DMSO) or compounds for $6 \mathrm{~h}$ or $24 \mathrm{~h}$.

For MTT assay, $30 \mu \mathrm{l}$ MTT $(5 \mathrm{mg} / \mathrm{ml})$ solution was added to the culture medium. After incubated for $3 \mathrm{~h}$ at $37^{\circ} \mathrm{C}, 100 \mu \mathrm{l}$ 'Triplex Solution' (10\% SDS-5\% isobutanol-12 $\mathrm{mM} \mathrm{HCl}$ ) was added to each well for $16 \mathrm{~h}$, and then absorbance was measured at $570 \mathrm{~nm}$ by a spectrophotometer (Infinite M1000 Pro, TECAN, Mannedorf, Switzerland). 
For trypan blue exclusion staining, the trypan blue stock solution $(0.4 \%$, from Sigma-Aldrich, Saint Louis, MO, USA) was mixed 1: 9 with cell suspension. Cells were then counted manually using a hemocytometer under microscope.

\section{ROS analysis}

$\mathrm{Mm} \mathrm{C}$-induced ROS generation was determined by 2', 7'-dichlorofluorescin diacetate $\left(\mathrm{DCFH}_{2}-\mathrm{DA}\right.$, from Sigma-Aldrich) as previous described [8]. Briefly, A549 cells were treated with $10 \mu \mathrm{M} \mathrm{DCFH} \mathrm{H}_{2}-\mathrm{DA}$ at $37^{\circ} \mathrm{C}$ for 30 min before further analysis by flow cytometry (FACS Aria II, BD, San Jose, California, USA). For mitochondria (1 $\mathrm{mg} / \mathrm{ml}), 10 \mu \mathrm{M} \mathrm{DCFH}{ }_{2}-\mathrm{DA}$ were added to $\mathrm{Ca}^{2+}$ induced swelling buffer (as shown below in the $\mathrm{Ca}^{2+}$ induced mitochondrial swelling assay section) and fluorescence (488 nm excitation, $525 \mathrm{~nm}$ emission) was recorded over 15 min by a spectrophotometer [49]. Means and standard errors of 3 replicates per point are shown.

\section{Proteomic analysis}

Proteomic analysis was performed by PTM Biolab, Inc. (Hangzhou, Zhejiang, China). Briefly, A549 cell were treated with $1 \mu \mathrm{M} \mathrm{Mm} \mathrm{C}$ for $6 \mathrm{~h}$ or $12 \mathrm{~h}$ and proteins of whole-cell lysates were extracted, separated and digested. Peptides were then separated and identified by liquid chromatography (LC)-electron spray ionization (ESI)tandem mass spectrometry (MS/MS) analysis.

The resulting MS/MS data were processed using Mascot search engine. Tandem mass spectra were searched against Swiss-Prot human database. For peptide search, trypsin/P was specified as cleavage enzyme allowing up to 2 missing cleavages. Mass accuracy was set to 10 ppm for precursor ions and 0.02 Da for fragment ions. Carbamidomethylation on Cys, TMT-6Plex on peptides $\mathrm{N}$-term and Lys were included as fixed modification and oxidation on Met was specified as a variable modification. For result export, peptide ion score was set $\geq 20$. For protein quantitation, a protein was required to contain at least two unique peptides. Protein quantitative ratios were weighted and normalized relative to the median ratio in Mascot. Only proteins with significant quantitative ratios between the two treatments $(\mathrm{P}<0.05)$ and with fold changes $\geq 1.2$ or $\leq 0.83$ were considered to be differentially expressed.

For KEGG (Kyoto Encyclopedia of Genes and Genomes) pathway-based enrichment analysis of differentially expressed proteins, KEGG database was used to identify enriched pathways by a two-tailed Fisher's exact test to test the enrichment of the differentially expressed proteins against all identified proteins. Correction for multiple hypothesis testing was carried out using standard false discovery rate control methods.

\section{Isolation of mouse liver mitochondria}

Female ICR mice weighing approximately $25 \mathrm{~g}$ were used in this study. All mice experiments in this study were approved by Institute of Oceanology Laboratory Animal Care and Ethics Committee in accordance with the animal care and use guidelines.

Mitochondria from ICR mouse liver were prepared according to standard differential centrifugation procedures at $1000 \mathrm{~g}, 10000 \mathrm{~g}$ and $7000 \mathrm{~g}$ at $4{ }^{\circ} \mathrm{C}$ for $10 \mathrm{~min}$ as described [49]. Isolation medium contained $250 \mathrm{mM}$ sucrose, $20 \mathrm{mM}$ HEPES, $10 \mathrm{mM} \mathrm{KCl}, 1.5 \mathrm{mM}$ $\mathrm{MgCl}_{2}$ and $1 \mathrm{mM}$ EDTA (wash medium without EDTA) at $\mathrm{pH}$ 7.4.

\section{Respiration of cells and mitochondria}

Oxygen consumption rate was polarographically monitored by an oxygraph (Hansatech, Norfolk, UK). The respiration medium of A549 cells $\left(1.5 \times 10^{6}\right.$ cells $\left./ \mathrm{ml}\right)$ was RPMI 1640 medium. While mitochondria $(1.5 \mathrm{mg} /$ $\mathrm{ml}$ ) were incubated in respiration medium containing $125 \mathrm{mM}$ sucrose, $10 \mathrm{mM}$ HEPES, $65 \mathrm{mM} \mathrm{KCl}, 10 \mathrm{mM}$ $\mathrm{KH}_{2} \mathrm{PO}_{4}, 0.1 \mathrm{mM}$ EDTA, $5 \mathrm{mM}$ glutamate and $5 \mathrm{mM}$ malate at $\mathrm{pH} 7.4$ [49].

\section{Mitochondrial swelling assay in isotonic potassium acetate}

To test the protonophoric properties of compounds, mitochondrial swelling assay was measured in isotonic potassium acetate as previously described [50]. Briefly, $\mathrm{Mm} \mathrm{C}$ or $\mathrm{CCCP}$ were added into $100 \mu \mathrm{l}$ isotonic potassium acetate medium $(145 \mathrm{mM}$ potassium acetate, $5 \mathrm{mM}$ Tris, $0.5 \mathrm{mM}$ EDTA, $1 \mu \mathrm{M}$ rotenone and $1 \mu \mathrm{M}$ valinomycin at $\mathrm{pH}$ 7.4) in 96-well transparent plate. Then mitochondria (1 $\mathrm{mg} / \mathrm{ml}$ ) were resuspended with $100 \mu \mathrm{l}$ isotonic potassium acetate medium and added in 96-well transparent plate. Absorbance of mitochondrial suspension at $600 \mathrm{~nm}$ was recorded immediately with shaking over $10 \mathrm{~min}$ by a spectrophotometer. Means and standard errors of 3 replicates per point are shown.

\section{$\mathrm{Ca}^{2+}$ induced mitochondrial swelling assay}

PTP opening was monitored by $\mathrm{Ca}^{2+}$ induced mitochondrial swelling assay as previous described [51]. Briefly, $\mathrm{Mm} \mathrm{C}$ or Cs A or Mm C together with Cs A were added into a medium (250 $\mathrm{mM}$ sucrose, $10 \mathrm{mM}$ HEPES, $6 \mathrm{mM}$ succinate, $2.5 \mu \mathrm{M}$ rotenone and $40 \mu \mathrm{M} \mathrm{CaCl}_{2}$ at pH 7.4) in 96-well transparent plate. Then mitochondria $(1 \mathrm{mg} / \mathrm{ml})$ were resuspended with $100 \mu 1$ medium $(250$ $\mathrm{mM}$ sucrose, $10 \mathrm{mM}$ HEPES, $6 \mathrm{mM}$ succinate and 2.5 $\mu \mathrm{M}$ rotenone at $\mathrm{pH}$ 7.4) and added in 96-well transparent plate. Absorbance of mitochondrial suspension at 540 $\mathrm{nm}$ was recorded immediately with shaking over $10 \mathrm{~min}$ 
by a spectrophotometer. Means and standard errors of 3 replicates per point are shown.

\section{Statistical analysis}

All data were shown only if three independent experiments showed consistent results. Data were graphically represented as mean \pm SEM. Treatment means were compared by one-way analysis of variance followed by Tukey's test using GraphPad Prism software (San Diego, CA, USA). P values $<0.05$ were considered statistically significant $\left({ }^{*} \mathrm{p}<0.05,{ }^{* *} \mathrm{p}<0.01,{ }^{* * *} \mathrm{p}<\right.$ $0.001)$.

\section{ACKNOWLEDGMENTS AND FUNDING}

We thank Prof. Guangce Wang (Institute of Oceanology, Chinese Academy of Sciences) for the help with the oxygen electrode measurements. This work was supported by AoShan Talents Program supported by Qingdao National Laboratory for Marine Science and Technology (No.2015ASTP), Natural Science Outstanding Youth Fund of Shandong Province (No.JQ201607), Taishan Young Scholar Program of Shandong Province, "100-Talent Project" of Chinese Academy of Sciences for Chaomin Sun. Special Fund for Postdoctoral Innovation Project of Shandong Province (No. 201502032), Qingdao Postdoctoral Application Research Funded Project for Shan Kuang.

\section{CONFLICTS OF INTEREST}

The authors have no conflicts of interest.

\section{REFERENCES}

1. Stewart B, Wild CP. World cancer report 2014. World. 2016.

2. Ferlay J, Soerjomataram I, Dikshit R, Eser S, Mathers C, Rebelo M, Parkin DM, Forman D, Bray F. Cancer incidence and mortality worldwide: Sources, methods and major patterns in GLOBOCAN 2012. International Journal of Cancer. 2015; 136:E359-E86.

3. Newman DJ, Cragg GM. Natural Products as Sources of New Drugs from 1981 to 2014. J Nat Prod. 2016; 79:629-61.

4. Bouchet P, Duarte CM. The exploration of marine biodiversity: scientific and technological challenges. Fundación BBVA. 2006; 33.

5. Blunt JW, Copp BR, Munro MHG, Northcote PT, Prinsep MR. Marine natural products. Natural Product Reports. 2011; 28:196-268.

6. Crawford AD, Jaspars M, De Pascale D, Andersen JH, Reyes F, Ianora A. The marine biodiscovery pipeline and ocean medicines of tomorrow. Journal of the Marine
Biological Association of the United Kingdom. 2016; 96:151-8.

7. Trachootham D, Zhou Y, Zhang H, Demizu Y, Chen Z, Pelicano H, Chiao PJ, Achanta G, Arlinghaus RB, Liu J, Huang P. Selective killing of oncogenically transformed cells through a ROS-mediated mechanism by $\beta$-phenylethyl isothiocyanate. Cancer Cell. 2006; 10:241-52.

8. Sun X, Ai M, Wang Y, Shen S, Gu Y, Jin Y, Zhou Z, Long Y, Yu Q. Selective induction of tumor cell apoptosis by a novel P450-mediated reactive oxygen species (ROS) inducer methyl 3-(4-nitrophenyl) propiolate. J Biol Chem. 2013; 288:8826-37.

9. Raj L, Ide T, Gurkar AU, Foley M, Schenone M, Li X, Tolliday NJ, Golub TR, Carr SA, Shamji AF, Stern AM, Mandinova A, Schreiber SL, et al. Selective killing of cancer cells by a small molecule targeting the stress response to ROS. Nature. 2011; 475:231-4.

10. Szatrowski TP, Nathan CF. Production of large amounts of hydrogen peroxide by human tumor cells. Cancer Res. 1991; 51:794-8.

11. Toyokuni S, Okamoto K, Yodoi J, Hiai H. Persistent oxidative stress in cancer. FEBS Lett. 1995; 358:1-3.

12. Trachootham D, Alexandre J, Huang P. Targeting cancer cells by ROS-mediated mechanisms: a radical therapeutic approach? Nat Rev Drug Discov. 2009; 8:579-91.

13. Wang J, Yi J. Cancer cell killing via ROS: to increase or decrease, that is the question. Cancer Biol Ther. 2008; 7:1875-84.

14. Watson J. Oxidants, antioxidants and the current incurability of metastatic cancers. Open biology. 2013; 3:120144.

15. Wondrak GT. Redox-directed cancer therapeutics: molecular mechanisms and opportunities. Antioxidants \& redox signaling. 2009; 11:3013-69.

16. Kowaltowski AJ, de Souza-Pinto NC, Castilho RF, Vercesi AE. Mitochondria and reactive oxygen species. Free Radic Biol Med. 2009; 47:333-43.

17. Bernardi P, Petronilli V, Di Lisa F, Forte M. A mitochondrial perspective on cell death. Trends Biochem Sci. 2001; 26:112-7.

18. Debatin KM, Poncet D, Kroemer G. Chemotherapy: targeting the mitochondrial cell death pathway. Oncogene. 2002; 21:8786-803.

19. He J, Ford HC, Carroll J, Ding S, Fearnley IM, Walker JE. Persistence of the mitochondrial permeability transition in the absence of subunit c of human ATP synthase. Proceedings of the National Academy of Sciences. 2017; 114:3409-14.

20. Morciano G, Giorgi C, Bonora M, Punzetti S, Pavasini R, Wieckowski MR, Campo G, Pinton P. Molecular identity of the mitochondrial permeability transition pore and its role in ischemia-reperfusion injury. J Mol Cell Cardiol. 2015; $78: 142-53$. 
21. Brookes PS, Yoon Y, Robotham JL, Anders MW, Sheu SS. Calcium, ATP, and ROS: a mitochondrial love-hate triangle. Am J Physiol Cell Physiol. 2004; 287:C817-33.

22. Kowaltowski AJ, Castilho RF, Vercesi AE. Mitochondrial permeability transition and oxidative stress. FEBS Lett. 2001; 495:12-5.

23. Crompton M, Ellinger H, Costi A. Inhibition by cyclosporin $\mathrm{A}$ of a $\mathrm{Ca}^{2+}$-dependent pore in heart mitochondria activated by inorganic phosphate and oxidative stress. Biochem J. 1988; 255:357-60.

24. Hawas UW, Shaaban M, Shaaban KA, Speitling M, Maier A, Kelter G, Fiebig HH, Meiners M, Helmke E, Laatsch H. Mansouramycins A-D, cytotoxic isoquinolinequinones from a marine streptomycete. J Nat Prod. 2009; 72:2120-4.

25. McKee TC, Ireland CM. Cytotoxic and antimicrobial alkaloids from the Fijian sponge Xestospongia caycedoi. J Nat Prod. 1987; 50:754-6.

26. Pettit GR, Collins JC, Herald DL, Doubek DL, Boyd MR, Schmidt JM, Hooper JNA, Tackett LP. Isolation and structure of cribrostatins 1 and 2 from the blue marine sponge Cribrochalina sp. Canadian Journal of Chemistry. 1992; 70:1170-5.

27. Choi YH, Park A, Schmitz FJ, van Altena I. Perfragilins A and $\mathrm{B}$, cytotoxic isoquinolinequinones from the bryozoan Membranipora perfragilis. J Nat Prod. 1993; 56:1431-3.

28. Milanowski DJ, Gustafson KR, Kelley JA, McMahon JB. Caulibugulones A-F, novel cytotoxic isoquinoline quinones and iminoquinones from the marine bryozoan Caulibugula intermis. J Nat Prod. 2004; 67:70-3.

29. Hoyt MT, Palchaudhuri R, Hergenrother PJ. Cribrostatin 6 induces death in cancer cells through a reactive oxygen species (ROS)-mediated mechanism. Invest New Drugs. 2011; 29:562-73.

30. Brisson M, Foster C, Wipf P, Joo B, Tomko RJ Jr, Nguyen $\mathrm{T}$, Lazo JS. Independent mechanistic inhibition of cdc25 phosphatases by a natural product caulibugulone. Mol Pharmacol. 2007; 71:184-92.

31. Lee HC, Yin PH, Lu CY, Chi CW, Wei YH. Increase of mitochondria and mitochondrial DNA in response to oxidative stress in human cells. Biochem J. 2000; 348 Pt 2:425-32.

32. Chung YM, Kim JS, Yoo YD. A novel protein, Romo1, induces ROS production in the mitochondria. Biochem Biophys Res Commun. 2006; 347:649-55.

33. Omiya S, Hikoso S, Imanishi Y, Saito A, Yamaguchi O, Takeda T, Mizote I, Oka T, Taneike M, Nakano Y, Matsumura Y, Nishida K, Sawa Y, et al. Downregulation of ferritin heavy chain increases labile iron pool, oxidative stress and cell death in cardiomyocytes. J Mol Cell Cardiol. 2009; 46:59-66.

34. Lu X, Kambe F, Cao X, Kozaki Y, Kaji T, Ishii T, Seo H. $3 \beta$-Hydroxysteroid- $\Delta 24$ reductase is a hydrogen peroxide scavenger, protecting cells from oxidative stress-induced apoptosis. Endocrinology. 2008; 149:3267-73.
35. Zhong Q, Putt DA, Xu F, Lash LH. Hepatic mitochondrial transport of glutathione: studies in isolated rat liver mitochondria and H4IIE rat hepatoma cells. Arch Biochem Biophys. 2008; 474:119-27.

36. Baek JY, Han SH, Sung SH, Lee HE, Kim YM, Noh YH, Bae SH, Rhee SG, Chang TS. Sulfiredoxin protein is critical for redox balance and survival of cells exposed to low steady-state levels of H2O2. J Biol Chem. 2012; 287:81-9.

37. Nishio C, Yoshida K, Nishiyama K, Hatanaka H, Yamada $\mathrm{M}$. Involvement of cystatin $\mathrm{C}$ in oxidative stress-induced apoptosis of cultured rat CNS neurons. Brain Res. 2000; 873:252-62.

38. Kajimoto H, Hashimoto K, Bonnet SN, Haromy A, Harry G, Moudgil R, Nakanishi T, Rebeyka I, Thebaud B, Michelakis ED, Archer SL. Oxygen activates the Rho/Rhokinase pathway and induces RhoB and ROCK-1 expression in human and rabbit ductus arteriosus by increasing mitochondria-derived reactive oxygen species: a newly recognized mechanism for sustaining ductal constriction. Circulation. 2007; 115:777-88.

39. Liu YX, Wang J, Guo J, Wu J, Lieberman HB, Yin Y. DUSP1 is controlled by $\mathrm{p} 53$ during the cellular response to oxidative stress. Mol Cancer Res. 2008; 6:624-33.

40. Lo YY, Wong JM, Cruz TF. Reactive oxygen species mediate cytokine activation of c-Jun NH2-terminal kinases. J Biol Chem. 1996; 271:15703-7.

41. Wan J, Liu T, Mei L, Li J, Gong K, Yu C, Li W. Synergistic antitumour activity of sorafenib in combination with tetrandrine is mediated by reactive oxygen species (ROS)/ Akt signaling. British journal of cancer. 2013; 109:342-50.

42. Bull AT, Stach JE. Marine actinobacteria: new opportunities for natural product search and discovery. Trends in microbiology. 2007; 15:491-9.

43. Maciel EN, Vercesi AE, Castilho RF. Oxidative stress in $\mathrm{Ca}^{2+}$-induced membrane permeability transition in brain mitochondria. J Neurochem. 2001; 79:1237-45.

44. Batandier C, Leverve X, Fontaine E. Opening of the mitochondrial permeability transition pore induces reactive oxygen species production at the level of the respiratory chain complex I. J Biol Chem. 2004; 279:17197-204.

45. Walter L, Nogueira V, Leverve X, Heitz MP, Bernardi P, Fontaine E. Three classes of ubiquinone analogs regulate the mitochondrial permeability transition pore through a common site. J Biol Chem. 2000; 275:29521-7.

46. Fontaine E, Ichas F, Bernardi P. A ubiquinone-binding site regulates the mitochondrial permeability transition pore. $\mathrm{J}$ Biol Chem. 1998; 273:25734-40.

47. Lee HC, Wei YH. Mitochondrial biogenesis and mitochondrial DNA maintenance of mammalian cells under oxidative stress. Int J Biochem Cell Biol. 2005; 37:822-34.

48. Bernardi P. Modulation of the mitochondrial cyclosporin A-sensitive permeability transition pore by the proton electrochemical gradient. Evidence that the pore can be 
opened by membrane depolarization. J Biol Chem. 1992; 267:8834-9.

49. Pereira LC, Miranda LFC, de Souza AO, Dorta DJ. BDE154 induces mitochondrial permeability transition and impairs mitochondrial bioenergetics. Journal of Toxicology and Environmental Health, Part A. 2014; 77:24-36.

50. Kenwood BM, Weaver JL, Bajwa A, Poon IK, Byrne FL, Murrow BA, Calderone JA, Huang L, Divakaruni
AS, Tomsig JL. Identification of a novel mitochondrial uncoupler that does not depolarize the plasma membrane. Molecular metabolism. 2014; 3:114-23.

51. Ligeret H, Barthelemy S, Zini R, Tillement JP, Labidalle $\mathrm{S}$, Morin D. Effects of curcumin and curcumin derivatives on mitochondrial permeability transition pore. Free Radical Biology and Medicine. 2004; 36:919-29. 